\title{
Twitterature Aleksandra Acimana i Emmetta Rensina jako wariant twitter fiction
}

\author{
Abstract \\ Twitterature by Alexander Aciman and Emmett Rensin as a Variant of Twitter Fiction
}

The following article aims to present a study on twitterature - an intersection of literature and Twitter and a variant of twitter fiction. The latter has become increasingly popular since the advent of Twitter at the end of the first decade of this century and has dwarfed longer and traditional narratives. The subject of analysis will be Twitterature. The World's Greatest Books in Twenty Tweets or Less (2009) by Alexander Aciman and Emmett Rensin. The author of this article argues that parodic reworkings of 76 literary classics for the 21 st century readers should be analysed as a variant or subgenre rather than a fully developed literary genre. Therefore the analytical tools have been appropriated from literary realm rather than new media studies. The author's aim is not to present an outline of electronic literature or its typology, since that has been exhausted by other researchers. The main objective is rather to comment on one of the variants of electronic literature, which undertook a postmodernist dialogue with classic hypertexts (hypertexts in the Genettian sense of the word). Thus the most relevant aspects investigated here include generic boundaries, the role of the reader, inherent features as well as (Twitter) format and style respectively.

Keywords: Twitterature, Twitter, Twitter fiction, electronic literature.

Słowa kluczowe: Twitteratura, Twitter, Twitter fiction, e-literatura.

\section{Wprowadzenie}

Rozkwit mediów cyfrowych oraz spopularyzowanie Twittera narzuciły konieczność przedefiniowania tradycyjnego pojmowania literatury, materialnej książki czy kultury druku. Współcześnie Twitter stał się również platformą kontaktów z czytelnikami i jest wykorzystywany do tworzenia i udostępniania wypowiedzi literackich czy paraliterackich. Medium to szczególnie upodobali sobie entuzja- 
ści literatury cyfrowej ${ }^{1}$. Sama e-literatura stanowi zróżnicowany i genologicznie niejednorodny przedmiot badawczy ${ }^{2}$. Powodem zróżnicowania się gatunków w obrębie literatury cyfrowej są ,różne sposoby ich odbioru, lecz także struktura i uwarunkowania kodu, na którym te utwory się zasadzają"’3. Popularne gatunki to chociażby hipertekst, ${ }^{4}$ flarf ${ }^{5}$ czy twitteratura, a w obrębie każdego z nich funkcjonują odrębne warianty lub tendencje. Na szczególną uwagę zasługuje twitter fiction, wariant twitteratury odnoszący się zasadniczo do prozy narracyjnej o proweniencji cyfrowej. Stanowi on jeden z popularnych gatunków hybrydycznych na styku literatury cyfrowej i literatury drukowanej. Twitter fiction ${ }^{6}$ występuje przede wszystkim w sieci, a dopiero wtórnie w formie drukowanej, choć należy zaznaczyć, że drukowanie twitteratury to bardziej wyjątek niż reguła czy zauważalna tendencja. Jedną z ciekawszych odmian czy trendów w literackim użyciu Twittera są parodystyczne streszczenia klasycznych pozycji z kanonu literatury światowej. Narodzin wyżej wspomnianego wariantu należy upatrywać w 2009 roku. Wówczas to ukazał się zbiór tekstów zatytułowany Twitterature. The

1 W niniejszym artykule termin „literatura cyfrowa” będzie używany synonimicznie z „e-literatura".

2 Por. U. Pawlicka Literatura elektroniczna. Stan badań w Polsce, „Teksty Drugie” 2014, nr 3, oraz eadem, Towards a History of Electronic Literature [w:] Comparative Literature and Culture 2014, nr 16.5. Piszą o tym między innymi: P. Marecki, Liternet.pl, Kraków 2003; Co dalej literaturo? Jak zmienia się wspótcześnie pojęcie i sytuacja literatury, red. A. Brodzka-Wald, H. Gosk, Warszawa 2008; M. Janusiewicz, Literatura doby Internetu. Interaktywność i multimedialność tekstu, Kraków 2013. Por. także L. Al Sharaqi, Twitter Fiction: A New Creative Literary Landscape, „Advances in Language and Literary Studies" 2016, August, vol. 7, no. 4.

3 Za: http://www.techsty.art.pl/magazyn/magazyn7/literatura_elektroniczna_czym_jest_1.html (dostęp: 10.10.2018).

4 Termin stworzony w 1965 roku przez Teda Nelsona odnosi się do hipermediów o charakterze tekstowym. W Nelsonowskim hipertekście organizacja danych jest nielinearna i niesekwencyjna. Tekst jest „,rozbity na fragmenty, które na wiele sposobów połączone są ze sobą odsyłaczami”. Innymi słowy, tekst „,rozgałęzia się lub działa na żądanie czytelnika” (za: http://techsty.art.pl/hipertekst/definicje.htm [dostęp: 10.10.2018]). Przykładem hipertekstowych powieści mogą być afternoon a story Michaela Joyce'a, Victory Garden Stuarta Moulthropa czy Patchwork Girl Shelley Jackson. Warto nadmienić, że utwór M. Joyce'a - klasyczna już powieść e-literatury - dostępny jest w polskim przekładzie jako popoludnie. pewna historia. Jest to przy okazji bodaj pierwsze i jedyne do tej pory thumaczenie tego kanonicznego hipertekstu na jakikolwiek język obcy.

5 Gatunek e-literatury noszący miano flarfu określa poezję cechującą się ,intensywnym wykorzystaniem sieci jako generatora treści (wiersze są komponowane z półprzypadkowych treści znalezionych w internecie) oraz społeczności w tym sensie, że utwory innych autorów wchodzą $\mathrm{z}$ sobą w interakcje. Wiersze są bowiem tworzone, poprawiane, zmieniane przez innych, włączane do innych utworów, plagiatowane itp., w przestrzeni półpublicznej”. „Flarfowaty” stał się synonimem niewłaściwego, niespójnego czy niepoprawnego politycznie tekstu (za: http://poewiki.vot.pl/index. php?title=Flarf [dostęp 10.10.2018]).

6 Modę na twitter fiction zainicjował amerykański pisarz Nicholas Belardes. W latach 2008-2010 na platformie Twittera opublikował 358-tweetową powieść Small Places. Założył dla niej oddzielne konto, a losy bohaterów śledziły niemal 4 tysiące użytkowników. Dwa lata później w jego ślady poszła pisarka, która swoje opowiadanie Black Box opublikowała w sieci, pisząc je kilkoma haustami w ciągu 10 dni. Propagatorem tej formy stał się także David Mitchell, z tym że jego opowiadanie The Right Sort (2014) pojawiło się najpierw w wersji cyfrowej, a następnie drukowanej. Nieco inaczej należałoby klasyfikować 100 Greek Myths in 100 Tweets Lucy Coats, która, podobnie jak Tweetterature Acimana i Rensina, stanowi przykład digital-born printed book. 
World's Greatest Books in Twenty Tweets or Less Aleksandra Acimana i Emmetta Rensina, w którym dwóch amerykańskich studentów zaadaptowało klasyczne teksty literatury zachodniej na potrzeby nowego medium. Twitterature, która stanowi przykład publikacji drukowanej, o proweniencji cyfrowej (tzw. digital-born printed book), będzie głównym przedmiotem analizy niniejszego artykułu. $\mathrm{Z}$ racji funkcjonowania na styku literatury cyfrowej i drukowanej, twitter fiction niewątpliwie nastręcza trudności związanych z dostosowaniem metodologii do przedmiotu badawczego, a co za tym idzie - doborem właściwego języka opisu. Jest to kluczowa kwestia dla opisu e-literatury, która funkcjonuje w odmiennym porządku kulturowym. Kwestię tę omawia w swoim artykule Urszula Pawlicka ${ }^{7}$. Jak zauważa, badacze, posiłkując się teoriami i kategoriami z literatury tradycyjnej, często narażają się na wspomniane niedostosowanie czy niekompatybilność. Zdaniem autorki niniejszego artykułu, w przypadku analizy parodystycznych tekstów Alexandra Acimana i Emmetta Rensina uzasadniony będzie pewien kompromis metodologiczny. Chcąc wykazać i omówić podobne strategie formalne czy narracyjno-stylistyczne, należy czerpać z repertuaru postmodernistycznej teorii intertekstualności. Na potrzeby analizy będziemy więc posługiwać się typologią Gerarda Genette'a ${ }^{8}$. Przyjęcie perspektywy wyłącznie literaturoznawczej może się wydać redukcjonistyczne, natomiast forma, którą przyjęli Aciman i Rensin, w dużej mierze narzuca dobór takich narzędzi interpretacyjnych. Jednocześnie gatunkowa hybrydyczność twitter fiction obliguje do posługiwania się nowomedialnymi kodami, które zastosowali sami autorzy, parodiując styl postów na Twitterze wraz z jego netspeak. Według wiedzy autorki, o ile istnieją terminy ukute do prób opisu literatury cyfrowej, o tyle niewiele jest terminów odnoszących się do e-literatury tworzonej za pomocą platformy takiej jak Twitter. Oprócz wspomnianego już języka opisu i narzędzi badawczych, istotna w procesie interpretacyjnym jest także rola samego badacza uwięzionego i funkcjonującego w nowej literacko-kulturowej i nowomedialnej rzeczywistości.

Istotne aspekty w dyskusji nad postmodernistycznymi tekstami Acimana i Rensina będą dotyczyły odpowiednio: zdefiniowania gatunkowej istoty Twitterature i jej podstawowych właściwości, statusu i roli odbiorcy w procesie recepcji oraz przekształceń w obrębie struktury dzieła. Te ostatnie zostaną omówione najszerzej w niniejszym artykule.

7 U. Pawlicka, Literatura elektroniczna.... Oprócz dyskursu wywodzącego się z tradycyjnej literatury, autorka omawia cztery inne odmiany dyskursu o literaturze cyfrowej. Jej zdaniem ten pierwszy wydaje się najmniej narażony na niedostosowanie metodologii do przedmiotu badawczego.

8 G. Genette, Palimpsesty. Literatura drugiego stopnia, thum. M. Milecki [w:] Wspólczesna teoria badań literackich za granica. Antologia, red. H Markiewicz, t. 4, cz. 2, Kraków 1992. W niniejszym artykule będę się posługiwać terminem „hipertekst” w ujęciu Genette'a. Nie należy go jednak mylić z Nelsonowskim hipertekstem stosowanym homonimicznie przez badaczy literatury cyfrowej. 


\section{Twitterature i jej aspekty}

Twitterature, w ujęciu Acimana i Rensina, ma kompozycję złożoną, wielotweetową, choć liczba tweetów nie jest w żaden sposób skonwencjonalizowana. Podobnie jak flash fiction, wyróżnia ją swoistość kompozycyjna czy redukcyjność ${ }^{9}$. Z założenia pojedynczy rozdział, czy też ,leksja” (by posłużyć się terminologią stosowaną w literaturze cyfrowej), nie powinien przekraczać 140 znaków. Ponadto zorientowana jest na emocjonalną reakcję odbiorcy i zawiera lub sugeruje kompletną historię opartą na fabule/opowieści. Powinna być rozrywkowa lub zmuszać do refleksji. Jak sugeruje sama nazwa, immanentną właściwością tej odmiany e-literatury jest hybrydyczność, Twitterature jest bowiem amalgamatem stylistyczno-gatunkowym, którego dwa elementy przynależą do różnych języków oraz systemu społeczno-kulturowego. Natomiast sam jej status gatunkowy jest dość niejasny. Po pierwsze, w zestawieniu z tekstem kanonicznym jest mniej trwała i efemeryczna, po drugie wpisane są weń wartościowanie i hierarchiczność. Genologicznie Twitterature Acimana i Rensina można sklasyfikować jako niemimetyczną parodię i trawestację, przy jednoczesnej dominancie tej pierwszej. Teksty obu autorów cechuje zamysł satyryczny, zawierają bowiem refleksję na temat zarówno literatury, jak i współczesnych praktyk kulturowych.

Jeśli zaś chodzi o strukturę stweetowanych utworów kanonu literatury światowej, Aciman i Rensin bez wątpienia zachowali pierwotny schemat fabularny, przejmując pierwotne elementy świata przedstawionego, bohaterów oraz a/chronologiczną sekwencję zdarzeń, które wyznaczają kompozycję poszczególnych hipertekstów ${ }^{10}$. Jednocześnie wybrane przez autorów cechy narracji czy też tropy i manieryzmy stylistyczne, utożsamiane ze stylem lub narracją tekstu pierwotnego, pełnią w tekście późniejszym jedynie funkcję odwoławczą. Z kolei tweetostruktura i zawartość semantyczna tekstów przesycona netspeak jest pochodną zamysłu autorskiego i elementem licentia poetica Acimana i Rensina.

Jeśli zaś chodzi o stosunek samych autorów do klasyki, ich literackie przedsięwzięcie, jak zaznaczają we wstępie do Twitterature, to parodystyczna, odzwierciedlająca ducha współczesności odpowiedź na przestarzałe w swojej formie powieści kanonu. Uważają oni, że w swojej dotychczasowej formie są niedostępne i przytłaczają językiem i kompozycją, co może zniechęcać odbiorcę przyzwyczajonego do skrótowości. Skrótowość idąca w parze z lakonicznością jest niejako imperatywem zdominowanej przez internet i media społecznościowe współczesności. Tak więc tweetoliteratura, którą serwują nam autorzy, ma być z założenia lekkostrawną przekąską z dodatkiem netspeak. Jak czytamy dalej we wstępie, uwspółcześniona wersja klasyki stanowi hołd-pastisz i podwójną karykaturę (również Twittera). Teksty te stanowią osobliwy wyraz wdzięczności amerykańskich studentów skierowany do klasyków zachodniej literatury, albowiem z jednej strony gloryfikują mistrzów literatury, z drugiej spłycają i infantylizują złożoność hipotekstów. Sami autorzy tak oto uzasadniają cel literackiego eksperymentu:

9 Por. M. Leś, Flash fiction. Krótko o najkrótszych opowieściach [w:] Tradycja i przeszłość genologii, red. D. Kulesza, Białystok 2013.

10 Termin w rozumieniu Genette'a. 
Uwolniliśmy biednego Hamleta z rygorystycznych ograniczeń, jakie nałożyła nań szesnastowieczna literatura, i upodobniliśmy do ciebie drogi czytelniku. Czyniąc z niego odlotowego młodzieńca, nie uszczknęliśmy ani grama z [pierwotnej] mądrości, piękna, dowcipu czy też niepokoju ${ }^{11}$.

Kolejną istotną kwestią są status oraz rola odbiorcy Twitterature. W strukturę tekstów Acimana i Rensina wpisane są intersubiektywne reguły, które narzucają pewien rodzaj interpretacji. Sposób i przebieg lektury narzuca nie tylko sam zamysł autorów, ale także jawne i ukryte sygnały, które przygotowują odbiorcę do ,ściśle określonego sposobu recepcji" ${ }^{12}$. Jeśli zaś chodzi o kompetencje odbiorcy Twitterature, pod uwagę należałoby wziąć przede wszystkim znajomość sparodiowanych przez autora klasyków, kulturowe uwarunkowania, kody popkultury czy znajomość współczesnych technologii nowomedialnych, które decydują o odbiorze hipotekstu. Jak bowiem słusznie zauważa Michał Markowski, „sens dzieła powstaje na przecięciu dwóch perspektyw: tekstu i recepcji, czyli złożonego oddziaływania samego dzieła oraz recepcji historycznie [i kulturowo] uwarunkowanego czytelnika"13.

Ostatni aspekt, który zostanie omówiony najszerzej, dotyczy przekształceń w obrębie struktury dzieła literackiego. W klasyfikacji przekształceń w obrębie Twitterature można przyjąć kilka strategii. Jako pierwszą warto wymienić dopisywanie fragmentów niewystępujących w pierwotnym utworze. Choć strategię tę przywołuje na swoim blogu ${ }^{14}$ Urszula Pawlicka, nie wyjaśnia ona jednak, jakie elementy zostają rozwinięte oraz czym podyktowane są takowe działania Acimana i Rensina. Warto się zatem zastanowić, czy dopisywanie polega na naddawaniu znaczeń i czy opiera się na rozwinięciu potencjalności tekstu kanonicznego. Kolejna kwestia z tym związana dotyczy wspólnych cech rozwiniętych elementów. Autorzy często dopisują wątki kultury popularnej, stosując w formie analogii kody, które czytelnicy łatwo odczytają. Strategia ta ma niekiedy na celu naddanie znaczeń. Dzieje się tak na przykład w przypadku tekstu Pani Dalloway, w którym autorzy dopisali dwa subwersywne tweety:

([Narrator/Virginia Woolf in Mrs Dalloway]) Perhaps I should jump out of a window, too, that might get me away from this ridiculous, oppressive society

Or a river. Yeah, that's it. A river - 82)

Ich przewrotność polega na tym, że słowa należą raczej do Virginii Woolf niż protagonistki@FlowerGirl (analogonu Klarysy Dalloway). Prześmiewczo potraktowano tu zarówno samobójcze myśli Woolf, jak i Septimusa Smitha.

Druga kategoria, również przywołana przez Pawlicką, to wprowadzanie wątków popkultury XX i XXI wieku. Ta bardzo popularna strategia pojawia się prak-

11 Twitterature. The World's Greatest Books in Twenty Tweets or Less, eds. Aciman A., Rensin E., London 2009, s. xiii: „We have liberated poor Hamlet from the rigorous literary constraints of the sixteenth century and made him - without losing an ounce of wisdom, beauty, wit or angst - a happening youngster. Just like you, dear reader", przeł. K.Sz.

12 M. Markowski, A. Burzyńska, Teorie literatury XX wieku. Podręcznik, Kraków 2009, s. 101.

13 Ibid., s. 102.

$14 \mathrm{http} / / /$ niedoczytania.pl/o-kontrowersyjnej-stronie-twitteratury/ (dostęp: 3.03.2018). 
tycznie w każdym ze stweetowanych tekstów, a (pop)kulturowe analogie dotyczą najczęściej filmów, muzyki oraz ikon literatury i kultury:

(Old Hags say Macbeth is killed by no man of woman born. Relieved. The Terminator not invented yet $)^{15}$

(Gatsby is so emo $)^{16}$

(Ophelia just pulled a Virginia Woolf. Funeral is on the way) ${ }^{17}$

(I'm like a Russian Voldemort minus Rasputin) ${ }^{18}$

([Grendel] looks like Mickey Rourke $)^{19}$

([Faustus to himself] But as Rocky says, no pain, no gain $)^{20}$

([Pip on Estella] I love her, but ...I don't want to marry Sylvia Plath over here) ${ }^{21}$

([Romeo to the Capulets] Make love, not war) ${ }^{22}$

([Sherlock Holmes] Robert Downey Jr playing me in a film? Totally cool. Perfect) ${ }^{23}$

([Jane Eyre] This would make a great Hugh Grant flick) $)^{24}$

(The Canterbury Tales] Yeoman...looks like Tom Hanks in Cast Away) ${ }^{25}$

Operując takimi kodami, autorzy częstokroć dodają niewystępujące w pierwowzorze fragmenty, które odsyłają czytelnika do utrwalonych w kulturze popularnej elementów. Stosując częste nawiązania i porównania z idolami/ikonami, Aciman i Rensin odwołują się do historyczno-kulturowych kompetencji czytelnika, tak by mógł on rozpoznać kody kulturowe czy literackie.

Trzeci typ działań można określić mianem transformacji stylistycznych. W ramach tej strategii autorzy Twitterature zastosowali między innymi przejście z rejestru formalnego do nieformalnego, wprowadzili wyrażenia slangowe oraz wulgaryzmy, stylizując stweetowane teksty na mowę potoczną:

([Paradise Lost]) What? They almighty knows everything? Asshole sent Gabriel - the motherfuckin archangel himself - to warn Adam and the first lady $)^{26}$

([Beowulf]) What a bad ass monster. He likes to eat dudes' heads. Heads! That's intense. Ah, fuck it' I'll deal in the morning. I've gotta crash $)^{27}$

([King Lear] What? Cordelia loves me only as much as she should? What effrontery! For that she will get naught. Nada. Zip $)^{28}$

([Robinson Crusoe] What if there are canibals on the Island? .... Nah, there ain't ...SHIT. A FOOTPRINT. CANIBALS! $)^{29}$

([Tristram Shandy]) @Mom: It's a cock, piss and shit story, Ma, and the fuckin' best of this kind...the best of its motherfucking kind) $)^{30}$

15 Twitterature..., s. 12.

16 Ibid., s. 14.

Ibid., s. 18. Tu akurat bardziej odwołanie do kultury wysokiej niżeli popularnej.

Ibid., s. 25.

Ibid., s. 27.

Ibid., s. 32.

Ibid., s. 37 .

Ibid., s. 56.

Ibid., s. 63.

Ibid., s. 114.

Ibid., s. 132.

Ibid., s. 2.

Ibid., s. 27.

Ibid., s. 40.

29 Ibid., s. 55.

30 Ibid., s. 78. 
Język tekstów Acimana i Rensina jest przede wszystkim slangowy i w przeważającej mierze seksistowski, wyróżnia go mnogość seksualnych aluzji, czego wymowną ilustracją jest słowniczek terminów zamieszczony na końcu zbioru tekstów. Znajdziemy w nim aż osiem różnych slangowych odniesień do seksu. Dla przykładu w składającej się z 19 tweetów parodii Lady Chatterley's Lover D.H. Lawrence'a można doliczyć się aż 14 określeń i skojarzeń seksualnych. Jednocześnie w jednym $\mathrm{z}$ metatekstowych ${ }^{31}$ tweetów, będącym zarazem uwagą na stronie, narrator stwierdza: ,I’ve got plenty of sex puns left, don’t worry!”, wyjawiając w ten sposób czytelnikowi, że ma jeszcze w zanadrzu całe mnóstwo seksualnych żartów i gier słownych ${ }^{32}$.

Kolejne działanie, które w swojej klasyfikacji ujęła także Pawlicka, dotyczy wykorzystania języka sieci (netspeak), z jego skrótami, emotikonami i hashtagami. Najpopularniejsze z nich to akronimy i skróty typu MILF, LOL, OMG, $\mathrm{STFU}^{33}$ czy amalgamaty pojęciowe, jak na przykład bromance (brother + romance), crunk (crazy drunk).

Ostatnia kategoria, z pewnością niewyczerpująca repertuaru przekształceń, to niewątpliwie podwójnie ukierunkowane działania parodystyczne. Autorzy Twitterature sparodiowali patetyczny język tekstów kanonicznych i ich erudycyjną niedostępność dla współczesnego odbiorcy. Paradoksalnie z tekstów tych wybrzmiewa prześmiewczy stosunek do Twittera, funkcjonującego jako synonim narcyzmu oraz ekshibicjonizmu. Bohaterowie parodii Acimana i Rensina to współczesne analogony literackich pierwowzorów, użytkownicy Twittera, Flickra i iPhonów. Są również mocno zanurzeni w kulturze popularnej i operują jej kodami, czego najlepszą ilustracją będzie przedstawiony w poniższej tabeli wybór przykładowych i zarazem najbardziej reprezentatywnych pseudonimów, które zostały odpowiednio pogrupowane w kategorie:

\begin{tabular}{|l|l|}
\hline Nick (hipertekst) & Skojarzenia z kulturą popularną \\
\hline $\begin{array}{l}\text { @BigMAC (Macbeth) } \\
\text { @ighwayToHell (Doctor Faustus) } \\
\text { Bovary) }\end{array}$ & $\begin{array}{l}\text { nasuwa skojarzenie z siecią MacDonald's } \\
\text { nawiązanie do kultowego utworu AC/DC } \\
\text { nawiązanie do kultowego amerykańskiego } \\
\text { serialu Desperate Housewives }\end{array}$ \\
\hline Nick (hipertekst) & $\begin{array}{l}\text { Nick zawiera imię głównego lub } \\
\text { drugoplanowego bohatera }\end{array}$ \\
\hline $\begin{array}{l}\text { @DarcyLover1815 (Emma) } \\
\text { @ piMp (Great Expectations) }\end{array}$ & $\begin{array}{l}\text { Darcy } \\
\text { Pip }\end{array}$ \\
$\begin{array}{l}\text { @eepDiggingWatson (Sherlock Holmes) } \\
\text { Knight) }\end{array}$ & $\begin{array}{l}\text { Watson } \\
\text { tytułowy Gewain }\end{array}$ \\
\hline
\end{tabular}

31 W kilku tekstach pojawiają się inne komentarze metatekstowe. „What an allegory!...” (33); „I curse the day I inexplicably transformed into a gigantic, six-legged metaphor!” (4); „What a Shakespearian twist of events!" (40, King Lear). Nie jest to jednak żadna strategia.

32 Ibid., s. 113.

33 Odpowiednio: „,mother I'd like to fuck”, „laughing out loud”, „oh my god” oraz „shut the fuck up". 


\begin{tabular}{|l|l|}
\hline Nick (hipertekst) & $\begin{array}{l}\text { Forma nicku zawierająca pewne symbole, } \\
\text { bądź inherentne właściwości pierwowzoru }\end{array}$ \\
\hline $\begin{array}{l}\text { @FlowerGirl (Mrs Dalloway) } \\
\text { @LittleBigMan (Gulliver's Travels) }\end{array}$ & $\begin{array}{l}\text { kwiaty jako symbol w Pani Dalloway } \\
\text { właściwości głównego bohatera } \\
\text { @ NotoriousDOC (Frankenstein) }\end{array}$ \\
$\begin{array}{l}\text { cechy dystynktywne } \\
\text { cechy wampiryczne, prześmiewczo }\end{array}$ \\
\hline
\end{tabular}

W kontekście recepcji hipotekstów przytoczone tu pseudonimy odzwierciedlają styl tweetów oraz pełnią kulturową funkcję odwoławczą dla czytelnika obcującego z nowomedialną rzeczywistością.

\section{Wnioski}

Jak pokazuje literackie przedsięwzięcie Acimana i Rensina, literatura popularna stała się partnerem współczesnych przemian i zarazem ,,polem eksperymentalnych, nowomedialnych badań tekstu, w kontekście semiotycznym, strukturalnym oraz w aspekcie możliwości rynkowych i komunikacyjnych"34. Jak słusznie zauważyła Urszula Pawlicka:

w takim ujęciu kulturowym literatura powstała przy użyciu nowych technologii wydaje się najpełniej realizować potencjał „rewolucyjny”, nie tylko przez zmianę medium i odnoszenie się tym samym do innego porządku kulturowo-społecznego, lecz także w wyniku wykorzystania różnych systemów semiotycznych ${ }^{35}$.

Twitterature, z racji swojej gatunkowo hybrydycznej formy, podwójnie determinuje odbiór tekstu, gdyż wiąże się z całym systemem społeczno-kulturowym i jako książka (jako medium), i jako jej stweetowana wersja. W przypadku hipertekstu Acimana i Rensina romans literatury wysokiej z Twitterem podważa status tej pierwszej. Co więcej, autorzy paradoksalnie afirmują fizyczność i linearność książki i jednocześnie kontestują jej kompozycję, chociażby poprzez zastosowanie leksji zamiast rozdziałów. Sprzeciwiają się przede wszystkim konwencjom literatury wysokiej oraz parodiują nowomowę i właściwości nowego medium, jakim jest Twitter. Choć podejmując parodystyczny eksperyment, autorzy nie zakładali głębszych zmian we współczesnej (e)literaturze i komunikacji literackiej, ich teksty wykazują subwersywny charakter i przeformułowują znaczenie tekstu i konwencji powieści, mimo że osadzone są w kulturze druku. Forma, którą przyjęli autorzy, to rodzaj sprzeciwu dla mimetycznej idei interpretacji jako biernego odtwarzania prawdy dzieła literackiego lub zawartej w nim intencji autorskiej. Nosząca znamiona karykatury transformacja nieodłącznie związana jest z wartościowaniem historycznego wzorca. Autorzy trywializują tekst macierzysty na płaszczyźnie stylistycznej, narracyjnej i fabularnej.

Kolejnym paradoksem jest jednak fakt, że napędzana przez konsumpcję „literatura na wynos" lub serwowana $\mathrm{w}$ formie przekąski z jednej strony infantylizuje

\footnotetext{
34 Maryla Hopfinger za: U. Pawlicka, Literatura elektroniczna. Stan badań w Polsce ..., s. 142.

35 U. Pawlicka, Literatura elektroniczna. Stan badań w Polsce..., s. 145.
} 
tekst kanoniczny i jego kompleksowość, z drugiej zaś umacnia w kanonie literatury światowej (a nie tylko zachodniej) status takich pisarzy jak William Szekspir, Jane Austen czy Virginia Woolf.

\section{Bibliografia}

Twitterature. The World's Greatest Books in Twenty Tweets or Less, eds. Aciman A., Rensin E., London 2009.

Al Sharaqi L., Twitter Fiction: A New Creative Literary Landscape, „Advances in Language and Literary Studies" 2016, August, vol. 7, no. 4.

Co dalej literaturo? Jak zmienia się wspótcześnie pojęcie i sytuacja literatury, red. A. Brodzka-Wald, H. Gosk, Warszawa 2008.

Genette G., Palimpsesty. Literatura drugiego stopnia, tłum. M. Milecki [w:] Wspótczesna teoria badań literackich za granica. Antologia, red. H Markiewicz, t. 4, cz. 2, Kraków 1992.

Hopfinger M., Zmiana miejsca? [w:] Co dalej literaturo? Jak zmienia się współcześnie pojęcie i sytuacja literatury, red. A. Brodzka-Wald, H. Gosk, Warszawa 2008.

Janusiewicz M., Literatura doby Internetu. Interaktywność i multimedialność tekstu, Kraków 2013.

Leś M., Flash fiction. Krótko o najkrótszych opowieściach [w:] Tradycja i przeszłość genologii, red. D. Kulesza, Białystok 2013.

Marecki P., Liternet.pl, Kraków 2003.

Markowski M., Burzyńska A., Teorie literatury XX wieku. Podręcznik, Kraków 2009.

Pawlicka U., Literatura elektroniczna. Stan badań w Polsce, „Teksty Drugie” 2014, nr 3, s. 141-161.

Pawlicka U., Towards a History of Electronic Literature, „Comparative Literature and Culture" 2014, nr 16.5. 